\title{
Questionnaire Development and Validity to Determine Intention Among Indian Youth to Help a Road Traffic Accident Victim
}

Neeti Rustagi ( $\nabla$ drneetigoswami@gmail.com )

AllMS Jodhpur https://orcid.org/0000-0003-3051-5411

Abhishek Jaiswal

All India Institute of Medical Sciences

Naveen Dutt

All India Institute of Medical Sciences Jodphur

Dervla Kelly

UL Graduate Entry Medical School: University of Limerick Graduate Entry Medical School

Arvind Sinha

All India Institute of Medical Sciences Jodhpur

\section{Pankaja Raghav}

All India Institute of Medical Sciences Jodphur

Mahavir Singh Rodha

All India Institute of Medical Sciences Jodphur

Vikas Rajpurohit

Dr S. N. Medical College Jodhpur

\section{Research article}

Keywords: "Theory of planned behavior", "Intention", "scale development", "Validation", "Road traffic accident

Posted Date: February 23rd, 2021

DOI: https://doi.org/10.21203/rs.3.rs-251362/v1

License: (c) (i) This work is licensed under a Creative Commons Attribution 4.0 International License. Read Full License 


\section{Abstract}

\section{Background}

Delay in receiving timely care after road traffic accidents (RTAs) result in higher morbidity and mortality, suggesting need of educational interventions for improving provision of first aid. Based on the theory of planned behaviour (TBP), the present study aims to develop and validate the scale to Measure of Intention to Help Road Accident Victim (MIHRAV) of young adults in a fast urbanizing Indian city.

\section{Methods}

A cross sectional survey was conducted among the college students of Jodhpur, Rajasthan. The initial MIHRAV questionnaire developed for study comprised of 26 self-reported items encompassing four main constructs: intention to help; social norms; attitude and self-efficacy. The validation process included face validity, content validity, exploratory factor analysis (EFA), confirmatory factor analysis (CFA) and reliability analysis.

\section{Results}

Six hundred ninety-five college students participated in this study. EFA extracted four factor structure containing 20 items. The CFA yielded good model fit with 19 items, and explained $79 \%$ of variance (chi square $=413.359, \mathrm{df}=140, \chi 2 / \mathrm{df}=2.95, \mathrm{CFI}=0.93$ and $\mathrm{TLI}=0.92$ and RMSEA $=0.05)$. The Cronbach's alpha indicated satisfactory internal consistency for questionnaire $(a=.88)$, and for subscales (social norms - $a=.62$, attitude $-a=.65$, perceived confidence- $a=.74$, and intention $a=.86$ ).

\section{Conclusions}

The final MIHRAV instrument is aligned with constructs of TPB. It included 19 items measuring intention to help ( 9 items); perceived confidence ( 4 items); attitude ( 3 items) and social norm ( 3 items). MIHRAV was found to be reliable and valid tool to assess young adult's intention to help road accident victims. Assessing and building this aspect has the potential to positively impact young adult's likelihood to intervene as first responders at RTAs.

\section{Background}

Road safety is a priority area for research as studies from the World Health Organization (WHO), (2018), show that approximately 1.35 million people die on the world's roads every year, while as many as 50 million others are injured. ${ }^{1}$ Man-made traffic accidents are a subject of immense concern in developing countries where the risk of dying in a road traffic crash is more than 3 times higher than in high-income countries. In India, in 2016, more than 150,000 people lost their lives in road traffic accidents and 4,80,652 injuries to $4,94,624$ persons were reported. Delayed access to care after road traffic accidents (RTAs) and distance to health centers are barriers to receiving timely care. ${ }^{2,3}$ Strengthening the emergency care 
systems that serve as the first point of contact is essential to ensuring timely and equitable access to care for the injured.

As per Sasser et al. ${ }^{4}$ the deaths of severely injured RTA patients occurring commonly due to airway compromise, respiratory failure or uncontrolled hemorrhage can be reduced by providing basic first aid measures. These first aid measures can be administered by trained volunteers and non-health professionals.

Given the gaps in organized prehospital care in India and other low- or middle- income countries, it has been suggested by the WHO that bystanders and laypeople must be taught the basics of care to trauma victims. ${ }^{5}$

Bystanders are defined as people who attend at the crash scene without any knowledge and skill about relief, rescue, and first aid to the RTAs victims. ${ }^{6}$ Sometimes, the congestion of laypeople at the crash scene can affect the relief forces' function leading to new crash for those who are observing the scene. ${ }^{6}$ However, in some cases, bystanders with adequate knowledge and understanding about aiding the injured can perform basic life support and initial measures for injury before arrival of the emergency organizations and in some cases, provide transportation. ${ }^{7,8}$ Therefore, they can play a significant role in reducing the consequences of RTAs.

Prosocial behaviour also known as helping behavior was defined by Stang et al. ${ }^{9}$ as a voluntary behavior performed with the intention of benefiting another person or group of people. Situational characteristics in form of "diffusion of responsibility"; "ambiguity in interpreting situation" and "cost reward analysis of the helping act" along with individual personality traits such as "adherence to norm of social responsibility"; "empathy"; "pro-social values"; "level of moral development" are hypothesized as predictors determining helping behavior especially in emergency situation. ${ }^{10-13}$

It is thought that providing training to laypeople in basic life support will improve the quality of care at the scene of RTAs, although little consideration has been given in these interventions to date on securing community engagement and maximizing participation. When teaching a new skill such as first response, educators focus mostly on the what and how (cognitive and psychomotor skills) rather than the why, which falls under the affective domain of learning. ${ }^{14}$

Previously several studies observed that information about helping or acquisition of skills does not always increase bystander responsiveness. ${ }^{8,15,16}$

The current approach to provide bystander training in form of self-directed learning or instructor-led course focuses upon building individual skills acquisition and retention. However, no evaluation of a learner's intention of volunteering help in incident of RTA or theory-based attempts to strengthen their intentions to engage in this behavior are reported so far. Further, currently there is no clear understanding 
of predictors likely to influence the strength of intention of young adults for providing care at the site of RTA.

According to well-validated theory based models (e.g., The Theory of Planned Behavior and Theory of Reasoned Action), an individual's behavioral intentions influence their motivation for engaging in a particular behavior. ${ }^{17}$ The theory of planned behavior (Ajzen, 1985,1988 ) is a social cognitive model used to predict people's behavior. It predicts that an individual's action largely reflect their attitudes, perceived norms and accepted behaviors and how well they believe they can perform the task. ${ }^{18,19}$ Intention focused model to enhance performance of CPR by bystanders was conceptualized by Panchal et al. ${ }^{20}$ Given the motivational component in giving first aid at the site of road traffic accident, we have selected the theory of planned behavior (TPB) as a useful framework to investigate the young adult intention to help at the scene of a road traffic accident. To our knowledge, TPB has not previously been applied to the prediction and understanding of bystander intention to help at the site of RTA.

\section{Objective:}

The aims of the present study were threefold: First, we used the TPB to model the relationship between norms, attitudes and perceived behavioral control on intentions to help the road traffic accident victim. Second, we evaluated whether attitude, subjective norm, perceived behavioral control could be regarded as good predictors of intention as specified in the Theory of Planned Behaviour. Third, we examined whether gender of an individual and their previous experience of helping an accident victim differ systematically with respect to the variables of the TPB.

\section{Methods}

This study was conducted as part of a funded project carried out to evaluate pre-hospital trauma care systems in Jodhpur, Rajasthan. This study consisted of two phases: Phase 1- questionnaire development and expert panel review and Phase 2-validation process.

\section{Phase 1: Questionnaire development}

A literature search was conducted to identify instruments that contain item related to factors influencing bystander's intention and helping behavior toward road traffic accident victims. The search was guided by using combination of different keywords including helping behavior, accidents, traffic accidents, bystanders, theory of planned behavior. The search engines included PubMed, Science Direct and Google Scholar. As research team was unable to identify any questionnaire related to measure of intention among young adults as bystanders, items for new instrument was framed through literature review as per the constructs of theory of planned behavior. ${ }^{22}$ Items and scoring were formulated in accordance with the paper by Francis et al. ${ }^{23}$

The provisional questionnaire contained questions on background information (age, gender, year of course, institute) and 27 self-reported items measuring the TPB constructs and perceived barriers of 
participants towards providing care to an accident victim. ${ }^{24,25}$. The initial instrument included a total of eight question domains. One item was removed after discussion with investigators because of unclear meaning leaving 26 items in the administered questionnaire(supplementary file 1). See Table 1 for initial instrument stratified by domain and item identifier. Each item was measured on a 7-point Likert scale (1=disagree/ unlikely/ unpleasant, 4=moderately and, 7=agree/ likely/ pleasant), high scores indicated a positive evaluation of the survey questionnaire. Previous experience of helping an accident victim was assessed with a single item dichotomously coded as "yes" and "no".

Two forward translations into Hindi were done by a linguistic expert and a medical doctor. Subsequently, the two sets of translated Hindi questionnaires underwent a backward translation into English by another linguistic expert and a medical doctor. The aim of this procedure was to identify translated items that closely match the original English version and to produce the Hindi version of the questionnaire

\section{Phase 2-Validation process}

The validity of MIHRAV was assessed using content validity, face validity, exploratory factor analysis (EFA), reliability analysis and confirmatory factor analysis (CFA). For content validity the peer review was invited by experts in field of emergency and trauma care and edits were made based on provided feedback. During face validity the investigator distributed the pre-final version of the questionnaire to the target population for reviewing grammar and appropriateness of the questionnaire. During this phase, ten young adults were cognitively debriefed. Ten respondents are sufficient for pilot testing using an interview type of pilot testing (Eremenco, 2005). ${ }^{26}$ The respondents were interviewed and asked to identify words or sentences that they did not understand. The respondents were encouraged to suggest alternate suitable words with which they were familiar. The feedback of participants was discussed with other investigators in the research team, and the final version of questionnaire was decided.

For subsequent factor analysis, from July 2019 till October 2019 the investigators administered the questionnaire among students studying in academic institutions of urban Jodhpur, Rajasthan. The data of educational institutions in urban Jodhpur was availed through annual report of year 2018-2019 on Government of Rajasthan website for higher and technical education. ${ }^{21}$ The colleges of medical, engineering, and other allied disciplines (pharmacy, nursing, and dental) were excluded, as students of these institutes couldn't be considered representative of general population due to their chosen study of discipline. Out of twenty-four professional colleges in the urban Jodhpur, six colleges were randomly chosen by lottery method (without replacement). These participants were likely to possess negligible or limited training to act at RTA site as learning opportunities are rare and are not part of academic curriculum for non- health students in this part of country. All the students present during data collection period in these institutes were approached for the study purpose. Students were invited to participate through the college administration and were repeatedly reminded to participate. A print version of the questionnaire was administered to the students in 30 minutes' class room setting on pre-specified days. Two research assistants were present throughout to support students. 
Sample size: Sample size was estimated on the basis of planned procedure for factor analysis. Thus, as recommended to ensure a conceptually clear factor structure for analysis, a sample of minimum 5 participants per item was considered. Thus, the required minimum sample size was estimated to be 150 (26 items were in the questionnaire). ${ }^{27}$

\section{Ethics approval: This study was part of an Indian Council of Medical Research project approved by the AllMS Jodhpur Ethics Committee. Ethical clearance for performing this study was obtained from the Institutional Ethics Committee (AlIMS / IEC/2018 /1188, dated 02.05.2018).}

\section{Informed Consent: All the eligible participants were informed about the purpose of the study, and were assured regarding the confidentiality of the information obtained. Written informed consent for participating in the study was obtained for all individual participants included in the study. No monetary reward was provided for participant willing to take part in the study. The items were not compulsory and participants had the option of abstaining from each question. The confidentiality of the dataset was maintained by removing the identifiers from the interview schedule.}

Statistical analysis: Responses were coded, and entered in Microsoft excel. No items were reverse coded for data analyses. The distribution of the responses was inspected for each item to eliminate items with a low discriminative power. These were (a) items with $95 \%$ or more of the given answers in the same category, and (b) items with a standard deviation lower than .75.

Statistical analysis was performed using STATA version 13.1 (StataCorp LP, College Station, TX, USA). Descriptive analyses were performed on all items, followed by exploratory factor analysis (EFA), and reliability analysis. Kaiser-Meyer-Olkin (KMO) test and Bartlett's test of sphericity were done for aptness of data for EFA. EFA was performed using maximum likelihood with oblique rotation (Promax). Factor retention was based on the Eigenvalue more than one, and point of inflexion on the Scree plot. Variables with factor coefficients of 0.40 or more were retained. The reliability of the questionnaire was determined by internal consistency (Cronbach's alpha) coefficient and a Cronbach's alpha coefficient $\geq 0.70$ and $\leq$ 0.90 was considered an indicator of reliable scale. ${ }^{28}$

Confirmatory factor analysis (CFA) was performed to evaluate relationships between structural paths and latent variables (factors) using AMOS 26.0. The hypothesized model was derived using the latent constructs of attitudes, norms, perceived confidence, and intentions as per TPB model. 
CFA was performed with the mean values of each domain identified and its respective factor identified in the EFA, however no cross-loadings were allowed.

Parameters were estimated for the CFA model based on the maximum likelihood procedure (sometimes called path analysis) involving fitting the variances and covariance's among observed scores. It was essential to identify the four-factor model in order to estimate the model parameters. In conducting CFA, no warning messages were received from AMOS 26.0 regarding parameter estimates. Based upon this information, the four-factor model passed the "rules" for identification. We also examined the assessment of universal fit pertaining to the quality of the model in SEM in order to support or reject its appropriateness for the population examined. The next step was to illustrate the observed (items) and unobserved (factors) in the hypothesized model (Figure 1). The observed variables are represented as rectangles; ellipses represent the unobserved variables (latent variables) and the circles represent measurement error. The arrow between the unobserved variable and the observed variable represents a regression path and its number represent the standardized regression weight. The arrow between a small circle and the observed variable represents a measurement error term.

For CFA, the recommendations of $\mathrm{Hu}$ and Bentler (1995) were followed and the model fit was evaluated by means of various goodness of fit indices. ${ }^{29} \mathrm{~A}$ statistically significant chi-square test suggests that model lack the fit to data. In addition to chi-square, use was made of chi-square divided by the degrees of freedom, which is less sensitive to sample size. For this estimate, values below three are considered satisfactory (Bollen\&Long, 1993). ${ }^{30}$ Other indices were the root mean square error of approximation (RMSEA), the tucker Lewis Index (TLI) and the comparative fit index (CFI). For the RMSEA, values below .05 are considered as a good fit, values between .05 and .08 as acceptable, and values higher than .08 as reasonable errors of approximation in the population (Browne \& Cudeck, 1992). ${ }^{31} \mathrm{CFI}$ compares the fit of a null model (i.e., when unobserved variables are uncorrelated and independent) with the fit of the researcher's model. ${ }^{32} \mathrm{~A} \mathrm{CFI}$ value of greater than 0.90 shows a psychometrically acceptable fit to the data. ${ }^{33}$ The GFI shows the degree of variance and covariance together explained by the model. The value of GFI ranges between 0 and 1 . A value of 1 indicates a perfect fit.

\section{Results}

A total of 695 participants responded to the questionnaire, of which 662 were included after removing the data with missed responses for one or more questions.

Sample characteristics: Mean age of male participants (mean 19.18 years; SD 1.9) was significantly higher compared to female (mean 18.82; SD 1.8) participants $\left[t{ }_{(660)}=2.49 ; p=0.013\right.$ ]. No significant difference was observed in formal years of education of male and female participants. Significantly more male participants (37.2\%) as compared to female participants $(23.1 \%)$ had previous experience of helping a road traffic accident victim [ chi square $(1)=15.30 ; p<0.001$ ] 
Item analysis: Mean and standard deviation of instrument items by behavioral domain is illustrated in Table 1. All showed sufficient variation across the response categories (i.e., less than $95 \%$ of responses on a single category and SD more than 0.75 ).

All participants with previous experience of helping an accident victim scored significantly higher $(p<0.05)$ on all items as compared to participants with no experience. For majority of items, male participants scored significantly higher $(\mathrm{p}<0.05)$ as compared to female participants except for following; perceived ability to learn and perform in pre-hospital trauma care training course (item $c$ and q); attitude toward administering care to road accident victim (item $h, n, s$ ) and influence of friends and bystanders at an accident site towards helping a RTA victim (item $b$ and bb). (Table 1)

\section{Exploratory factor analysis:}

The Kaiser-Meyer-Olkin (KMO) analysis was carried out to examine the criteria for identifying the factor structure. Since KMO index was 0.929 ('superb' according to Field, 2009) ${ }^{34}$ All KMO values for individual items were well above the acceptable limit of .5 (Field,2009) ${ }^{34}$ except for one item which was therefore removed ["item p"]. Bartlett test of sphericity was significant $(p<0.001)$. Therefore, the data was fit for identifying factors using exploratory factor analysis. EFA was conducted using maximum likelihood analysis with Promax rotation. For factor extraction, scree plot and Kaiser criterion with eigenvalue of more than 1 showed that the instrument contained four factors which represented $49.6 \%$ cumulative variance.

The item designation criteria (factor loading of more than 0.4 , and cross loading of less than 0.35 ) was used for reduction of the instrument to simple factor structure. Table 2 shows the pattern matrix of factor loading of each item with factor loading of more than 0.4 . Out of the original 26 items, a total of 20 items were retained in the EFA.

The first factor included nine items; the second factor included five items; the third factor and the four factor both included 3 items.

Reliability analysis: The summation of items within each factor yielded four subscales whose internal consistency ranged from 0.6 to 0.8 and thus indicated satisfactory internal reliability. ${ }^{35}$ Scale descriptive statistics and reliability for the scales derived and confirmed by factor analysis techniques is shown in Table 3.

\section{Confirmatory factor analysis:}

Based on visual display of factor loading, items related to "training attitude", "situational intention" and "situational confidence "were allowed to load on Intention; items related to "pro-social belief" and "willingness to provide care" were allowed to load on Attitudes; items related to "normative beliefs" and "training intention"were allowed to load on Social Norms; items related to "Execution confidence" and "universal situation likelihood" were loaded for Perceived confidence 
Focusing on Table 4 , the significant chi-square value $(\mathrm{p}<0.0001)$ does not imply support for the fourmodel factors in total sample. However, it should be noted that empirical studies showed that the $p$-value becomes significant if sample size is large enough. ${ }^{32,36,37}$

Based on Cohen's guidelines ${ }^{38}$, perceived confidence had moderate effect on intentions (standardized beta, $\beta=0.464$, $S E=.062, p<0.001$ ), attitude also had moderate effect on intention (standardized beta, $\beta=$ $0.558, \mathrm{SE}=.057, \mathrm{p}<0.001$ ). Inter-relationship between perceived confidence and attitude (standardized covariance $=0.597, \mathrm{SE}=0.053, \mathrm{p}<0.001$ ), perceived confidence and social norm (standardized covariance $=0.592, \mathrm{SE}=0.055, \mathrm{p}<0.001$ ), and attitude and social norm (standardized covariance $=0.841, \mathrm{SE}=0.037$, $\mathrm{p}<0.001$ ) were significant. In reviewing values of $\mathrm{GFI}, \mathrm{CFI}$, TLI and RMSEA in Table 2, it is evident that the four-factor model represents a very good fit to the total sample. The model accounted for $83.5 \%$ of variance in participant's behavioral intentions. (Figure 1).

Reliability analysis: The Cronbach's alpha indicated satisfactory internal consistency for questionnaire ( $a$ $=.88$ ) and for subscales (social norms $-a=.62$, attitude $-a=.65$, perceived confidence- $a=.74$, and intention $a=.86)$.

Inter scale correlations: The Pearson correlations coefficients $(r)$ between the four components were calculated using summated respondent scores on individual scale components. The proportion of linearly explained variance $\left(r^{2}\right)$ between components was estimated by squaring $r$ (Table 3 ). As this table indicates, the determinants are significantly inter-correlated and significant correlations are also observed for behavioral intention. The association between intention, perceived confidence, attitude and social norm were found to be substantial (with proportion of explained variance $>0.20$ ) indicating that young adults with intention to help at the site of RTA possess higher levels of execution confidence, pro-social beliefs and willingness to fulfil social responsibility. (Table 5)

Substantial association was also seen between normative influence and attitude $(r=0.54)$ thus, indicating that those who are willing to provide care and have pro-social beliefs are likely to have favorable training attitude and normative beliefs. Further, the results showed that attitude, perceived control and social norm are different constructs as inter-correlations was around 0.35 (Table 5)

Group differences: Accepting the changes concerning item loadings on specific factors that were revealed by the CFA, group differences were analyzed with respect to the changed composition of the scale. Intention, social norms, attitudes and perceived confidence differed significantly both for gender of participants and for individuals with and without previous experience of helping an accident victim. Group differences in responses to the items of the four scales are depicted in Table 1. Differences on item level are consistent with the direction of differences on scale level.

On scale level, individuals with previous experience of helping an accident victim scored significantly higher for intention $\left(t_{(482)}=-6.97, p<0.001\right)$; perceived confidence $\left(t_{(382)}=-8.66, p<0.001\right)$; attitude $(t$ $(451)=-5.45, p<0.001)$ and social norms $\left(t_{(443)}=-3.64, p<0.001\right)$. 
Group means for participants revealed significant difference between male and female participants with males reporting moderately strong intentions (Mean $=5.32$, SE .06); more positive attitude (Mean $=5.84$, SE .06); higher social norm (Mean = 5.47, SE .06) and perceived confidence (Mean = 4.27, SE .07) as compared to female participants. (Table 6)

\section{Discussion}

The purpose of the current study was to develop and validate a questionnaire determining intention of educated youth to engage in pro-social behavior at RTA site. The MIHRAV instrument was successfully developed and validated for use among Indian youths. Using factor analysis techniques, the investigational instrument was able to explain large proportion of the variance in intention to act in an incident of RTA. Bloom et al. (1956) postulated that behavioral learning is composed of three domains (knowledge, skills, and affective) and thus the ability for this instrument to explain more than half of variance exceeded a priori expectations. ${ }^{39}$

The EFA yielded four factors aligning with the TPB constructs. Standardized internal consistency of each subscale was satisfactory (Cronbach's alpha $>0.6$ ). Thus, instrument developed based on constructs from the TPB was observed to have strong construct validity and internal consistency.

The convergent and discriminant validities of these formulated items were further evaluated by confirmatory factor analysis. The items designed to assess a given latent variable (e.g., attitude toward the behavior) loaded highly on a single factor and had no strong cross-loading, that is, items designed to measure one construct (e.g., perceived behavioral control) did not exhibit significant loadings on other latent variables (e.g., intention). ${ }^{40}$ With factor analysis, the initial number of instrument items was reduced by $27 \%$ with final scale constituting 19 items out of 26 items.

This study establishes that the TPB is a useful tool to evaluate behavioral intention of young adults for providing assistance and care at RTA site.

The Intention construct was based on a 9-item subscale from factors based on "situational intention"; "situational confidence" and "training attitude". Based on these findings, intention-to-help at the site of RTA is a multidimensional construct dependent on the participant perceived confidence in communicating with bystanders, law authorities and health authorities for arranging help at accident site. The construct for Perceived confidence included four items from the domain of "execution confidence" and "universal situation likelihood" suggesting that the learner perception of own and others' possessing necessary skills required to help RTA victim drive this construct as discussed by Ajzen. ${ }^{40}$ The construct for social norms included three items from domain of "normative beliefs" and "training intention". This suggest that the learners' belief about social norms and their motivation to comply with these beliefs constitute this construct similar to behavioral intention model (BIM) proposed by Fishbein and Ajzen. ${ }^{41}$

The construct for attitude included three items mainly from domains of "pro-social belief and willingness to provide care". This was also in accordance to BIM where attitude toward the behavior is determined by 
the belief about the outcome of intended behavior and evaluation of these outcomes.

Male students and those with previous experience of helping an accident victim scored significantly higher for multiple items assessed. Ajzen has discussed personality traits, intelligence, demographic characteristics and other variables as background factors and hypothesized that TPB components mediate the effect of these background factors on intention and behavior. ${ }^{41}$

Considering the lifesaving nature of pre-hospital trauma care education, it is recommended that countries with evolving trauma care systems should train community volunteers as first responders to facilitate early and accurate care. ${ }^{5}$ Attention to behavioral intention and measuring it within population and participants is essential to identify and fill gap in understanding of the learner and to engage them better in future first aid related educational activities. ${ }^{42}$

For the health educator, the current instrument along with knowledge and skill-based assessments will be helpful in providing a holistic understanding while training youth in responding to incident of road traffic accidents.

Few of the major limitations in this study is that the MIHRAV questionnaire was tested on groups of college students in Rajasthan, India and thus the performance of this questionnaire on youths who are out of formal education or not in college is not known. Also, further studies are needed to investigate this instrument validity across other social determinants as race, age, education, socio-economic background in various population subgroups. Future studies may be planned using this instrument to understand the changes in learner attitude and intention towards responding to an RTA incident in pre-post learning environment. It is also known that presence of an intent-to-act may not necessarily result in an act in an actual emergency because of mitigating factors. ${ }^{41}$ Thus, utility of MIHRAV need to be further explored in form of longitudinal studies regarding helping behaviour at the site of road accident or the use of experimental deception-based studies to identify actual behaviours.

This study established the utility of well-established psychological theory (TPB) on a heterogeneous group of young adults. These students represent the section of educated Indian youth residing in fast urbanizing districts of India with limited or negligible experience of helping any RTA victim or acting as first respondent and represents an important section of population prone to road traffic accidents. Use of TPB to develop sub-scales of instrument offers a validated mechanism to carry out future research in similar or other population subgroups. This is also essential to establish meanings within each subscale for better interpretability by curricula developers, instructors, and program evaluators working to reduce mortality due to road traffic accidents.

The construction and validation of the designed instrument in various settings can provide researchers and pre-hospital trauma care curricula designers an insight regarding the affective state of bystanders present at the site of RTA incident and also essential learning experiences and inputs to instructors to inform content, engagement, and outcome goals of pre-hospital trauma care courses for the lay public and to maximize a volunteer's propensity to act in case of road traffic accident. Thus, we recommend 
integrating the instrument with bystander's educational program for helping road traffic accident victim, in order to help learner's, reflect on their own beliefs as well as societal norms and expectations while responding to RTA incident.

Informed consent: "Written Informed consent was obtained from all individual participants included in the study."

Ethical approval: "All procedures performed in studies involving human participants were in accordance with the ethical standards of the institutional and/or national research committee and with the 1964 Helsinki declaration and its later amendments or comparable ethical standards."

\section{List Of Abbreviations And Symbols Used}

RTA: Road traffic accidents

EFA: Exploratory factor analysis

CFA: Confirmatory factor analysis

TBP: Theory of Planned Behaviour

KMO: Kaiser-Meyer-Olkin

RMSEA: Root mean square error of approximation

TLI: Tucker Lewis Index

CFI: Comparative fit index

SD: Standard Deviation

GFI: Goodness of Fit Index

MIHRAV: Measure of Intention to Help a Road accident victim

SRMR: Standardized root mean square residuals

\section{Declarations}

Ethics approval and consent to participate: The study was approved by All India Institute of Medical Sciences, Jodhpur Ethics Review committee (number: AlIMS / IEC /2018/488) and was performed in accordance with the ethical standards ascribed by the 1964 Declaration of Helsinki and its later amendments. Approval was further obtained from the authorities of selected colleges. This study only involved participants who provided their written informed consent. The questionnaire was treated as confidential and anonymous; there was no personal information that could link the responses with any of 
the participants in the study. Each completed questionnaire was returned to the researcher on the same day of data collection.

Consent for publication: Not applicable.

Availability of data and materials: The datasets during and/or analysed during the current study is available from the corresponding author on reasonable request. The link for data repository is

https://mfr.osf.io/render?url=https\%3A\%2F\%2Fosf.io\%2Fnuk9b\%2Fdownload

Competing interests: The authors declare that they have no competing interests.

Funding: The study was funded by ICMR (Indian Council of Medical Research): ICMR 2016: 0274

Author Contributions: NR and AJ conceived the manuscript, performed the analyses, and wrote the manuscript. ND, VRP, AS, PR and MSR contributed to the data collection and measurements. NR, $\mathrm{AJ}$ and DK involved mainly in data analysis and its data quality management. NR provided overall supervision, edited the manuscript and had the responsibility for submitting for publication. All authors read and approved the final manuscript.

Acknowledgements: We wish to thank the participants and dean/ principals of academic institutions for providing us necessary permissions and support to conduct the study.

Author information (Affiliations)

NR, AJ, PR: Department of Community \& Family Medicine, All India Institute of Medical Sciences, Jodhpur, Rajasthan, India -342005.

MSR: Department of Trauma and Emergency Medicine, All India Institute of Medical Sciences, Jodhpur, Rajasthan, India -342005. 


\section{AS: Department of Paediatric Surgery, All India Institute of Medical Sciences, Jodhpur, Rajasthan, India -342005.}

\section{ND: Department of Pulmonary Medicine, All India Institute of Medical Sciences, Jodhpur, Rajasthan, India -342005.}

\section{VR: Department of Trauma and Emergency Medicine, M.D.M. Hospital \& Dr. S. N. Medical College Jodhpur, Rajasthan, India -342005.}

\section{DK: School of Medicine, Graduate Entry Medical School University of Limerick.}

\section{References}

1. World Health Organization. "Global status report on road safety 2015".

http://www.who.int/violence_injury_prevention/road_safety_status/2015/en/. Accessed on Sep 27, 2020.

2. Prakashy $\mathrm{C}$ et al. Pattern of road accidents system response and quality of services in emergency ward of a tertiary hospital in Delhi. Health and Population: Perspectives and Issues, 2013;36.3-4: 133151.

3. Gururaj G, Uthkarsh PS, Rao GN, Jayaram AN, Panduranganath V. Burden, pattern and outcomes of road traffic injuries in a rural district of India, International Journal of Injury Control and Safety Promotion,2016;23:1, 64-71, DOI: 10.1080/17457300.2014.945465.

4. Sasser SM, Varghese M, Joshipura M, Kellermann A. Preventing death and disability through the timely provision of prehospital trauma care.

5. Sasser S,Varghese M, Kellermann A, Lormand JD. Prehospital trauma care systems. Geneva: World Health Organization; 2005. Available from: http://www.who.int/violence_injury_prevention/publications/services/39162_oms_new.pdf.

6. Zavareh KD, Khankeh HR, Mohammadi R, Laflamme L, Bikmoradi A, Haglund BJ. Post-crash management of road traffic injury victims in Iran. Stakeholders' views on current barriers and potential facilitators. BMC Emergency Medicine,2009;9, 8.

7. Heidari M, Aryankhesal A, Zavareh DK. Laypeople roles at road traffic crash scenes: a systematic review, International Journal of Injury Control and Safety Promotion,2019;26:1, 82-91, DOI: 10.1080/17457300.2018.1481869.

8. Kamna S. Balhara, Nirma D. Bustamante, Anand Selvam, W. Tyler Winders, Amin Coker, Indi Trehan, Torben K. Becker \& Adam C. Levine (2019) Bystander Assistance for Trauma Victims in Low- and 
Middle-Income Countries: A Systematic Review of Prevalence and Training Interventions, Prehospital Emergency Care, 23:3, 389-410, DOI: 10.1080/10903127.2018.1513104.

9. Stang D.J, Wrightsman LS. A dictionary of social behavior and social research methods. Monterey, CA: Brooks/Cole; 1981.

10. Berkowitz L. Social norms, feelings, and other factors affecting helping behavior and altruism. In Berkowitz L, editors. Advances in experimental social psychology (Vol. 6). New York: Academic Press; 1972.

11. Mehrabian A, Epstein N. A measure of emotional empathy. Journal of Personality,1972;40, 525-543.

12. Staub E. Helping a distressed person: Social, personality, and stimulus determinates. In: Berkowitz L, editors. Advances in experimental psychology (Vol. 7). New York: Academic Press; 1974.

13. Emler NP, Rushton JP. Cognitive-developmental factors in children's generosity. British Journal of Social and Clinical Psychology, 1974;13, 277-281.

14. Taylor DCM, Hamdy H. Adult learning theories: Implications for learning and teaching in medical education: AMEE Guide No. 83, Medical Teacher, 2013;35:11, e1561-e1572, DOI: 10.3109/0142159X.2013.828153.

15. Schwartz SH, Gottlieb A. Participation in a bystander intervention experiment and subsequent everyday helping: Ethical considerations. Journal of Experimental Social Psychology. 1980;16,161171.

16. Katzev RD, Averill AK. Knowledge of the bystander problem and its impact on subsequent helping behavior. Journal of Social Psychology. 1984;123,223-230.

17. Fishbein M. A reasoned action approach to health promotion. Med Decis Making. 2008; 28:834844. [PubMed: 19015289].

18. Ajzen I. From intentions to actions: a theory of planned behavior. In: Kuhl J, Beckmann J, editors. Action control: from cognition to behavior. Berlin: Springer-Verlag; 1985. pp. 11-38.

19. Ajzen I. Attitudes, personality and behavior. Milton Keynes: Open University Press; 1988.

20. Panchal AR, Fishman J, Camp-Rogers T, Starodub R, Merchant RM. An "Intention-Focused” paradigm for improving bystander CPR performance. Resuscitation; 2015 Mar 1;88:48-51.

21. Government of Rajasthan. https://hte.rajasthan.gov.in/dept/dce/reports.php. Accessed on Sep 27, 2020.

22. Ajzen I. The theory of planned behavior. In: Organizational Behavior and Human Decision Processes. 1991. p. 179-211.

23. Francis J, Eccles MP, Johnston M, Walker AE, Grimshaw JM, Foy R, et al. Constructing questionnaires based on the theory of planned behaviour: A manual for health services researchers [Internet]. 2004 [cited 2019 Sep 26]. Available from: http://openaccess.city.ac.uk/id/eprint/1735/

24. Ajzen I, Manstead ASR. Changing health-related behaviors: An approach based on the theory of planned behavior. In: van den Bos K, Hewstone M, de Wit J, Schut H, Stroebe M, editors. The scope of social psychology: Theory and applications. New York: Psychology Press; 2007. pp. 43-63. 
25. Fishbein M, Ajzen I. Belief, attitude, intention, and behavior: an introduction to theory and research. Reading, MA: Addison-Wesley; 1975.

26. Eremenco SL, Cella D, Arnold BJ. A comprehensive method for the translation and cross-cultural validation of health status questionnaires. Eval Health Prof. 2005 Jun;28(2):212-32.

27. Kevin H. Kim (2005) The Relation Among Fit Indexes, Power, and Sample Size in Structural Equation Modeling, Structural Equation Modeling: A Multidisciplinary Journal, 12:3, 368-390, DOI: 10.1207/s15328007sem1203_2.

28. Leeuwen RV, Tiesinga LJ, Middel B, Post D, Jochemsen $H$. The validity and reliability of an instrument to assess nursing competencies in spiritual care. J Clin Nurs. 2009;18(20):2857-69.

29. Hu LT, Bentler PM. Evaluating model fit. In: Hoyle RH, editors. Structural equation modeling: Concepts, issues, and applications. Thousand Oaks, CA: Sage; 1995. pp. 76-99.

30. Bollen KA, Long JS, editors. Testing structural equation models. Newbury Park, CA: Sage; 1993.

31. Browne MW, Cudeck R. Alternative ways of assessing model fit. In: Bollen KA, Long JS, editors. Testing structural equation models. Newbury Park, CA: Sage; pp. 136-162.

32. Babyak M, Green S: Confirmatory factor analysis: An introduction for psychometric medicine researchers. Psychosomatic Medicine. 2010;72:587-597.

33. Tabachnick B, Fidell L: Using multivariable statistics. New York: Allyn \& Bacon; 2007.

34. Field A. Discovering Statistics Using SPSS. SAGE Publications; 2009. 857 p.

35. Taber KS. The Use of Cronbach's Alpha When Developing and Reporting Research Instruments in Science Education. Res Sci Educ 48, 1273-1296; 2018.

36. Dickey D: Testing the fit of our models of psychological dynamics using confirmatory methods. In: Tompson B, editors. Advances in social science methodology. Greenwich, CT: JAI Press; 1996.

37. Stevens J: Applied multivariate statistics for the social science Mahwah, New Jersey: Erlbaum; 2001.

38. Cohen J. Statistical power analysis for the behavioral sciences. Academic press; 2013.

39. Bloom BS, Engelhart MD, Furst EJ, Hill. H W, Krathwohl DR. Taxonomy of educational objectives. Book 1: Cognitive domain. White Plains, NY: Longman; 1956.

40. Ajzen I. The theory of planned behavior: Frequently asked questions. Human Behavior and Emerging Technologies. 2005.

41. Ajzen I. The theory of planned behavior. Organ Behav Hum Decis Process. 1991 Dec 1;50(2):179211.

42. Miller B, Pellegrino JL. Measuring intent to aid of lay responders: survey development and validation. Health Education \& Behavior. 2018 Oct;45(5):730-40.

43. Hu LT, Bentler PM. Cutoff criteria for fit indexes in covariance structure analysis: Conventional criteria versus new alternatives, Structural Equation Modeling: A Multidisciplinary Journal, 6:1, 1-55; 1999.

44. MacCallum RC, Browne MW, Sugawara HM. Power analysis and determination of sample size for covariance structure modeling. Psychological Methods. 1996; 1 (2):130-149. 


\section{Tables}

Table 1: Item, respective factor and mean score per group of the TPB items 


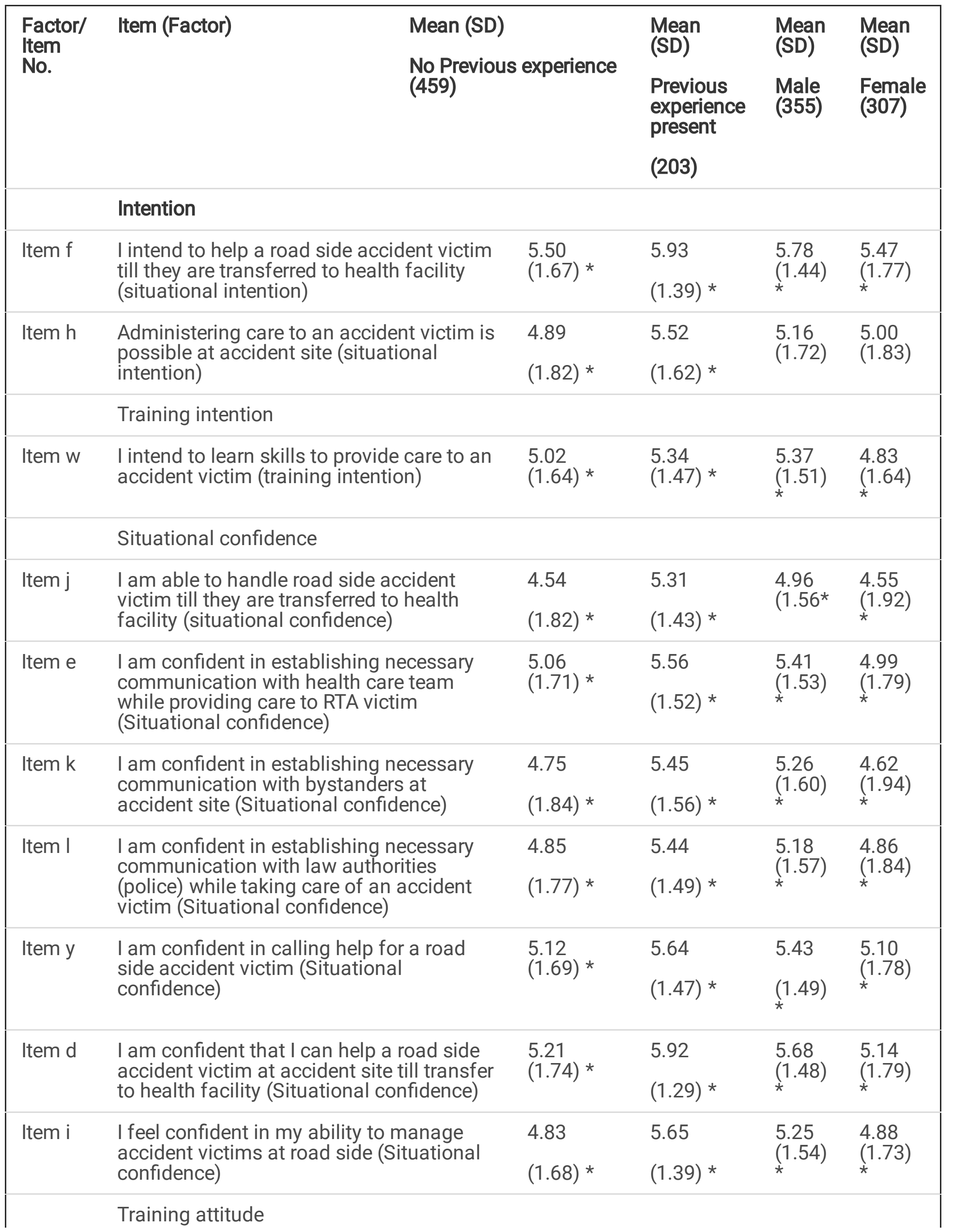




\begin{tabular}{|c|c|c|c|c|c|}
\hline Item c & $\begin{array}{l}\text { I feel confident in my ability to learn pre- } \\
\text { hospital trauma care course (training } \\
\text { attitude) }\end{array}$ & $\begin{array}{l}4.91 \\
(1.88) \text { * }\end{array}$ & $\begin{array}{l}5.53 \\
(1.50) *\end{array}$ & $\begin{array}{l}5.19 \\
(1.67)\end{array}$ & $\begin{array}{l}4.99 \\
(1.92)\end{array}$ \\
\hline Item & $\begin{array}{l}\text { I feel I can meet the challenge of } \\
\text { performing well in pre-hospital trauma } \\
\text { care course (training attitude) }\end{array}$ & $\begin{array}{l}4.39 \\
(1.77) \text { * }\end{array}$ & $\begin{array}{l}5.10 \\
(1.63) \text { * }\end{array}$ & $\begin{array}{l}4.66 \\
(1.66)\end{array}$ & $\begin{array}{l}4.55 \\
(1.86)\end{array}$ \\
\hline
\end{tabular}

\section{Execution confidence}

\begin{tabular}{|c|c|c|c|c|c|}
\hline Item o & $\begin{array}{l}\text { I am confident in ensuring airway } \\
\text { protection while providing care to accident } \\
\text { victim (Execution confidence) }\end{array}$ & $\begin{array}{l}3.73 \\
(2.02) \text { * }\end{array}$ & $\begin{array}{l}4.97 \\
(1.79) *\end{array}$ & $\begin{array}{l}4.32 \\
(1.92) \\
*\end{array}$ & $\begin{array}{l}3.87 \\
(2.12) \\
\star\end{array}$ \\
\hline Item p & $\begin{array}{l}\text { I am confident in assessing and managing } \\
\text { breathing in accident victim (Execution } \\
\text { confidence) }\end{array}$ & $\begin{array}{l}3.97 \\
(1.89) \text { * }\end{array}$ & $\begin{array}{l}5.12 \\
(1.64) *\end{array}$ & $\begin{array}{l}4.59 \\
(1.79) \\
\star\end{array}$ & $\begin{array}{l}4.02 \\
(1.97)\end{array}$ \\
\hline Item t & $\begin{array}{l}\text { I am confident in controlling excessive } \\
\text { bleeding while providing care to accident } \\
\text { victim (Execution confidence) }\end{array}$ & $\begin{array}{l}4.06(1.89) \\
\star\end{array}$ & $\begin{array}{l}5.00 \\
(1.78) *\end{array}$ & $\begin{array}{l}4.55 \\
(1.81) \\
\star\end{array}$ & $\begin{array}{l}4.12 \\
(1.99) \\
\star\end{array}$ \\
\hline Item u & $\begin{array}{l}\text { I am confident in preventing spinal injury } \\
\text { while providing care to accident victim } \\
\text { (Execution confidence) }\end{array}$ & $\begin{array}{l}3.35 \\
(1.92) \text { * }\end{array}$ & $\begin{array}{l}4.27 \\
(1.98) \text { * }\end{array}$ & $\begin{array}{l}3.92 \\
(1.96) \\
\star\end{array}$ & $\begin{array}{l}3.30 \\
(1.95) \\
\star\end{array}$ \\
\hline
\end{tabular}

\section{Willing to Provide care}

Item a Experience of helping a road side accident victim till they are transferred to health facility is pleasant (Willing to Provide care)

\begin{tabular}{|c|c|c|c|}
\hline 3.39 & 4.84 & 4.46 & 3.11 \\
\hline & $(1.96)$ * & & \\
\hline $\begin{array}{l}5.74 \\
(1.53) \text { * }\end{array}$ & 6.12 & $\begin{array}{l}5.90 \\
(1.44)\end{array}$ & $\begin{array}{l}5.80 \\
(1.46)\end{array}$ \\
\hline & $(1.21)$ * & & \\
\hline
\end{tabular}

Item $\mathrm{n} \quad$ Helping a road side accident victim till they reach health facility is my preferred choice (Willing to Provide care)

$(1.21)$ *

Pro-social beliefs

$\begin{array}{llllll}\text { Item m } & \begin{array}{l}\text { Providing appropriate care to an accident } \\ \text { victim will likely save life of patient (pro - } \\ \text { social beliefs) }\end{array} & \begin{array}{l}5.42 \\ (1.83) *\end{array} & \begin{array}{l}5.96 \\ (1.34) *\end{array} & \begin{array}{l}5.93 \\ (1.28)\end{array} & \begin{array}{l}5.19 \\ \text { (2.04) }\end{array} \\ \text { Item s } & \begin{array}{l}\text { Giving care to a roadside accident victim } \\ \text { is lifesaving skill (pro- social beliefs) }\end{array} & \begin{array}{l}5.50 \\ (1.67) *\end{array} & 5.92 & \begin{array}{l}5.72 \\ (1.38)\end{array} & \begin{array}{l}5.52 \\ (1.78)\end{array}\end{array}$

\section{Normative belief}

Item $r \quad$ People from my neighborhood are likely to help a road side accident victim till transfer to health facility (normative belief)

$\begin{array}{llll}4.78 & 5.38 & 5.12 & 4.78 \\ (1.76) * & & (1.61) & (1.79) \\ & (1.51) * & * & *\end{array}$

Item b My friends will appreciate me helping a road side accident victim (normative 


\begin{tabular}{|c|c|c|c|c|c|}
\hline & belief) & & $(1.67)$ * & & \\
\hline \multirow[t]{2}{*}{ Item v } & \multirow{2}{*}{$\begin{array}{l}\text { My work place colleagues will appreciate } \\
\text { me Helping a road side accident victim } \\
\text { (normative belief) }\end{array}$} & \multirow{2}{*}{$\begin{array}{l}5.15 \\
(1.78) *\end{array}$} & 5.54 & \multirow{2}{*}{$\begin{array}{l}5.41 \\
(1.66) \\
\star\end{array}$} & \multirow{2}{*}{$\begin{array}{l}5.11 \\
(1.82) \\
\star\end{array}$} \\
\hline & & & $(1.63)$ * & & \\
\hline & \multicolumn{5}{|l|}{ Universal situation likelihood } \\
\hline \multirow[t]{2}{*}{ Item x } & \multirow{2}{*}{$\begin{array}{l}\text { People are aware about providing care to } \\
\text { an RTA victim (Universal situation } \\
\text { likelihood) }\end{array}$} & 3.78 & 4.75 & \multirow{2}{*}{$\begin{array}{l}4.32 \\
(1.77)\end{array}$} & \multirow{2}{*}{$\begin{array}{l}3.81 \\
(1.85) \\
\star\end{array}$} \\
\hline & & $(1.8)$ * & $(1.71)$ * & & \\
\hline \multirow[t]{2}{*}{ Item z } & \multirow{2}{*}{$\begin{array}{l}\text { Road side accidents are common in my } \\
\text { area (Universal situation likelihood) }\end{array}$} & \multirow{2}{*}{$\begin{array}{l}3.41 \\
(2.04) \text { * }\end{array}$} & 4.27 & 3.83 & 3.49 \\
\hline & & & $(2.07)$ * & $\underset{\star}{(2.09)}$ & $(2.08)$ \\
\hline \multirow{2}{*}{$\begin{array}{l}\text { Item } \\
\mathrm{bb}\end{array}$} & \multirow{2}{*}{$\begin{array}{l}\text { Persons at the site of accident / } \\
\text { bystanders cooperate in providing care to } \\
\text { RTA victim (Universal situation likelihood) }\end{array}$} & \multirow{2}{*}{$\begin{array}{l}4.49 \\
(1.67) *\end{array}$} & 5.14 & \multirow{2}{*}{$\begin{array}{l}4.66 \\
(1.67)\end{array}$} & 4.72 \\
\hline & & & $(1.52)$ * & & $(1.62)$ \\
\hline
\end{tabular}

Table 2: Rotated Component matrix as per Exploratory factor analysis 


\begin{tabular}{|c|c|c|c|c|c|c|}
\hline \multicolumn{6}{|l|}{ Pattern Matrix ${ }^{a}$} & \multirow{3}{*}{$\begin{array}{l}\text { TPB } \\
\text { constructs }\end{array}$} \\
\hline \multirow[t]{2}{*}{ Factor/Item no. } & \multicolumn{4}{|c|}{ Factor } & \multirow[t]{2}{*}{ Item domain } & \\
\hline & 1 & 2 & 3 & 4 & & \\
\hline Item d & .769 & & & & Situational confidence & \multirow{9}{*}{ Intention } \\
\hline Item i & .708 & & & & Situational confidence & \\
\hline Item e & .646 & & & & Situational confidence & \\
\hline Item c & \multicolumn{4}{|l|}{.579} & Training attitude & \\
\hline Item I & \multicolumn{4}{|l|}{.489} & Situational confidence & \\
\hline Item k & \multicolumn{4}{|l|}{.460} & Situational confidence & \\
\hline Item j & \multicolumn{4}{|l|}{.456} & Situational confidence & \\
\hline Item $\mathrm{f}$ & \multicolumn{4}{|l|}{.454} & Situational intention & \\
\hline Item h & \multicolumn{4}{|l|}{.436} & Situational intention & \\
\hline Item u & \multicolumn{4}{|c|}{.885} & Execution confidence & Perceived \\
\hline Item t & \multicolumn{3}{|c|}{.659} & & Execution confidence & \multirow{4}{*}{ confidence } \\
\hline Item $x$ & \multicolumn{3}{|c|}{.572} & & Universal situation likelihood & \\
\hline Item o & \multicolumn{3}{|c|}{.520} & & Execution confidence & \\
\hline Item z & \multicolumn{3}{|c|}{.451} & & Universal situation likelihood & \\
\hline Item v & & & .598 & & Normative belief & \multirow{3}{*}{$\begin{array}{l}\text { Social } \\
\text { norms }\end{array}$} \\
\hline Item w & & & .525 & & Training intention & \\
\hline Item b & & & .461 & & Normative belief & \\
\hline \multicolumn{3}{|l|}{ Item n } & & .571 & Willing to Provide care & \multirow{3}{*}{ Attitude } \\
\hline Item $\mathrm{m}$ & & & & .559 & Pro-social beliefs & \\
\hline Item s & & & & 0.415 & Pro-social beliefs & \\
\hline
\end{tabular}

Table 3: Scale descriptive statistics 


\begin{tabular}{|llllll|}
\hline Scale & Scoring range & Mean & SD & Cronbach alpha & Items \\
EFA & & & & & \\
Intention & $1-63$ & 46.31 & 10.71 & 0.86 & 9 \\
Perceived confidence & $1-35$ & 19.85 & 6.90 & 0.74 & 5 \\
Attitude & $1-21$ & 17.07 & 3.66 & 0.65 & 3 \\
Social norm & $1-21$ & 15.82 & 3.95 & 0.62 & 3 \\
& & & & & \\
& & & & & \\
CFA & & & & & 3 \\
Intention & 63 & 46.31 & 10.71 & 0.86 & 3 \\
Perceived confidence & 28 & 16.18 & 5.86 & 0.74 & 3 \\
Attitude & $1-21$ & 17.07 & 3.66 & 0.65 & \\
Social norm & $1-21$ & 15.82 & 3.95 & 0.62 & \\
& & & & & \\
\hline
\end{tabular}

Note. EFA = exploratory factor analysis; CFA = confirmatory factor analysis

Table 4: Results of Fit Indices for 4-Factor Theory of Planned behavior model among study participants

\begin{tabular}{|c|c|c|c|c|c|c|c|c|c|}
\hline & $\begin{array}{l}\text { Chi } \\
\text { square }\end{array}$ & df & $\begin{array}{l}\text { (Chi } \\
\text { square/ } \\
\text { df) }\end{array}$ & CFI & TLI & GFI & RMSEA & $\begin{array}{l}90 \% \mathrm{Cl} \text { of } \\
\text { RMSEA }\end{array}$ & SRMR \\
\hline Ideal & & & $\begin{array}{l}\text { Between } \\
2 \text { to } 5\end{array}$ & $\begin{array}{l}>0.90 \\
43\end{array}$ & $\begin{array}{l}>0.90 \\
43\end{array}$ & $\begin{array}{l}>0.90 \\
43\end{array}$ & $\begin{array}{l}(<0.07) \\
44\end{array}$ & & $\begin{array}{l}(<0.05) \\
44\end{array}$ \\
\hline Model & 413.359 & 140 & 2.95 & 0.936 & 0.922 & 0.926 & 0.054 & $\begin{array}{l}0.048- \\
0.060\end{array}$ & 0.042 \\
\hline
\end{tabular}

Note. RMSEA = root mean error of approximation; SRMR = standardized root mean square residuals; GFI = goodness-of-fit index; TLI = the Tucker Lewis Index; CFI = comparative fit index. 
Table 5: Scale components correlations $(r)$ and linearly explained variance $\left(r^{2}\right)$ between components

\begin{tabular}{|lllll|}
\hline & Intention & Normative influence & PBC & Enabling attitude \\
\hline Intention & - & $0.565^{\star \star}(0.32)$ & $0.542^{\star \star}(0.29)$ & $0.610^{\star \star}$ \\
Social norm & - & - & & $(0.37)$ \\
& & & $0.358^{\star \star}(0.13)$ & $.537^{\star \star}$ \\
Perceived confidence & - & - & & $(0.29)$ \\
& - & - & $-350^{\star \star}$ \\
Attitude & - & - & - & $(0.12)$ \\
\hline
\end{tabular}

*Correlation is significant at 0.01 level (two tailed)

Table 6: Group mean difference for TPB constructs as per participants' gender and past experience of helping an accident victim 


\begin{tabular}{|c|c|c|c|c|c|c|}
\hline & Gender & $\mathbf{N}$ & Mean & $\begin{array}{l}\text { Std. Error } \\
\text { Mean }\end{array}$ & $t$ test (df) & $\begin{array}{l}P \\
\text { value }\end{array}$ \\
\hline \multirow{2}{*}{$\begin{array}{l}\text { Perceived } \\
\text { confidence }\end{array}$} & Male & 355 & 4.2768 & .07464 & $4.466(660)$ & $<0.001$ \\
\hline & Female & 307 & 3.7744 & .08474 & & \\
\hline \multirow[t]{2}{*}{ Attitude } & Male & 355 & 5.8498 & .05591 & $3.610(572)$ & $<0.001$ \\
\hline & Female & 307 & 5.5038 & .07782 & & \\
\hline \multirow[t]{2}{*}{ Social norm } & Male & 355 & 5.4714 & .06386 & $4.185(606)$ & $<0.001$ \\
\hline & Female & 307 & 5.0423 & .08020 & & \\
\hline \multirow[t]{3}{*}{ Intention } & Male & 355 & 5.3202 & .05703 & $4.052(599)$ & $<0.001$ \\
\hline & Female & 307 & 4.9439 & .07328 & & \\
\hline & $\begin{array}{l}\text { Past } \\
\text { experience }\end{array}$ & $\mathbf{N}$ & Mean & $\begin{array}{l}\text { Std. Error } \\
\text { Mean }\end{array}$ & t test (df) & $\begin{array}{l}P \\
\text { value }\end{array}$ \\
\hline \multirow[t]{2}{*}{$\begin{array}{l}\text { Perceived } \\
\text { confidence }\end{array}$} & No & 459 & 3.7315 & .06449 & $\begin{array}{l}-8.710 \\
(660)\end{array}$ & $<0.001$ \\
\hline & Yes & 203 & 4.7500 & .09827 & & \\
\hline \multirow[t]{2}{*}{ Attitude } & No & 459 & 5.5519 & .05918 & $-4.777(467)$ & $<0.001$ \\
\hline & Yes & 203 & 6.0000 & .07276 & & \\
\hline \multirow[t]{2}{*}{ Social norm } & No & 459 & 5.1561 & .06349 & $\begin{array}{l}-3.641 \\
(443)\end{array}$ & $<0.001$ \\
\hline & Yes & 203 & 5.5353 & .08254 & & \\
\hline \multirow[t]{2}{*}{ Intention } & No & 459 & 4.9494 & .05724 & $\begin{array}{l}-7.197 \\
(482)\end{array}$ & $<0.001$ \\
\hline & Yes & 203 & 5.5895 & .06808 & & \\
\hline
\end{tabular}

Figures 


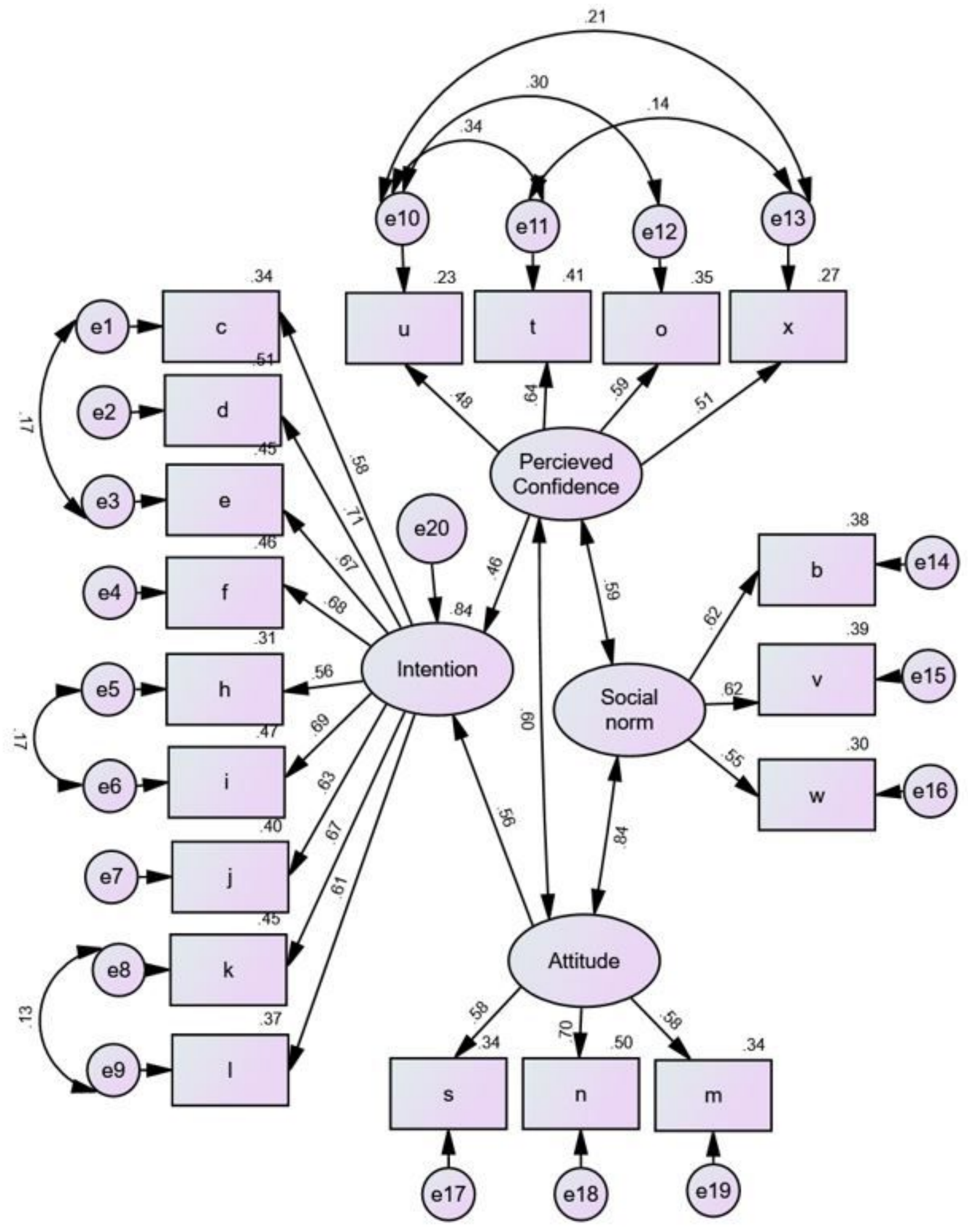

Figure 1

Confirmatory factor analysis (CFA) item domain loading by theory of planned behavior (TPB) construct. Note. Squared items represent measure questions domains, elliptical items represent latent TPB constructs. Solid lines indicate factor loading. No cross-loading were allowed.

\section{Supplementary Files}


This is a list of supplementary files associated with this preprint. Click to download.

- questionnaireBMCemMed.docx

- strobechecklistBMCemMedfinal.docx 